\title{
W20 em Riade: empoderamento econômico de mulheres na cúpula de 2020
}

W20 in Riyadh: economic empowerment of women at the 2020 summit

W20 en Riad: empoderamiento económico de las mujeres en la cumbre de 2020

Bárbara Lopes Campos 1

DOI: $10.5752 / \mathrm{P} .1809-6182.2021 \mathrm{v} 18 \mathrm{n} 1 \mathrm{pX}$

Recebido em: 25 de janeiro de 2021 Aprovado em: 03 de julho de 2021

\begin{abstract}
Resumo
A análise de conjuntura aborda a atuação do grupo de trabalho W20, dedicado à promoção da igualdade de gênero, durante a cúpula de Riade. A agenda de empoderamento econômico foi estudada a partir das recomendaçóes elaboradas durante a pandemia da COVID-19, e dos avanços e retrocessos no âmbito do G20.

Palavras-chave: Igualdade de gênero. G20. W20.
\end{abstract}

\begin{abstract}
The analysis addresses the work of the W20 working group, dedicated to promoting gender equality, during the Riyadh summit. The economic empowerment agenda was studied based on the recommendations made during the COVID-19 pandemic, and on the advances and setbacks within the G20's scope.

Key words: Gender equality. G20. W20.

\section{Resumen}

El análisis de coyuntura aborda el trabajo del grupo de trabajo W20, dedicado a promover la igualdad de género, durante la cumbre de Riad. Se estudió la agenda de empoderamiento económico a partir de las recomendaciones desarrolladas durante la pandemia COVID-19, y los avances y retrocesos en el ámbito del G2O.

Palabras clave: Igualdad de género. G20. W20.
\end{abstract}

1 Doutora em Ciência Política pela UFMG. Mestre em Relaçôes Internacionais pela PUC Minas. E-mail: barbara.angove@gmail. com 


\section{Introdução}

O grupo de trabalho do G20 dedicado à promoção da igualdade de gênero, o W20 (Women20), completou na última cúpula de Riade o seu quinto aniversário. Desde a sua criação em 2015, durante a cúpula de Istambul, o grupo tem ganhado importância como o órgáo que impulsiona as pautas relacionadas ao empoderamento econômico das mulheres, sempre em associação com outros grupos de trabalho, como o L20 (Trabalho), o C20 (Civil) e o B20 (Empresarial). O W20 tem produzido impactos nas declaraçôes dos líderes e nos comunicados oficiais do G20 nos últimos anos, ao recomendar metas para o aumento da participação das mulheres no mercado de trabalho, medidas para incentivar empresas e negócios liderados por mulheres e para estimular a inclusão digital de meninas e mulheres - dentre outras pautas.

A cúpula de Riade de 2020 ocorreu sob a presidência saudita, que estabeleceu um programa ambicioso em torno de três objetivos: salvaguardar o planeta, traçar novas fronteiras e empoderar pessoas. Nesse contexto, é interessante analisar os possíveis avanços promovidos na agenda do W20, seja por representar o seu quinto ano de trabalho; seja pela sua realização na capital saudita. Apesar de possuir um histórico de relaçôes de gênero desiguais e regidas pelas práticas da tutela (AL-RASHEED, 2013; MEIJER, 2010), desde 2016 a Arábia Saudita tem sido palco de mudanças importantes - como a criação do Conselho de Assuntos Familiares ${ }^{2}$, que aceleraram reformas em direção a conquistas de direitos das mulheres no país (WATSON-LYNN, 2020).

\footnotetext{
2 A inclusão de comitês técnicos nos conselhos facilitou mais de vinte mudanças legislativas, que têm garantido mais liberdade para as mulheres sauditas, como o direito a dirigir, a ter acesso a passaporte e a outros documentos, a solicitar o divórcio, e à eliminação de restriçóes, como no modo de se vestir em lugares públicos e de frequentar determinados espaços (WATSON-LYNN, 2020).
}

Apesar do engajamento do W20 e da atuaçâo do grupo de trabalho como uma ponte entre o G20 e a agenda internacional de gênero ${ }^{3}$, se tem observado limites nas últimas cúpulas em relação à capacidade do W20 de imputar compromissos objetivos por parte dos países membros (MOODY, 2015; KULIK, 2015; VÁZQUEZ, 2019). A meta mais audaciosa assumida pelo G20, até então, em relação à igualdade econômica de gênero, foi divulgada na cúpula de Brisbane, de 2014, e estabelece o objetivo de se reduzir o gap entre a participação masculina e feminina no mercado de trabalho em $25 \%$ até 2025 (KULIK, 2015). Porém, após cinco anos de atuação do W20, a meta permanece sem estratégias e comprometimentos claros para ser alcançada por parte dos países membros.

Ademais, a cúpula de Riade acabou sendo interceptada pela pandemia da COVID-19, que direcionou a agenda da organização e evidenciou outras camadas sobrepostas de desigualdade de gênero ao redor do mundo. Tendo em vista essa conjuntura, o artigo pretende analisar os avanços e limites da agenda da promoçáo da igualdade de gênero no âmbito do W20, tendo em vista os seus desdobramentos em 2020.

\section{A agenda de empoderamento econômico no contexto da COVID-19}

A cúpula de Riade, assim como toda a agenda política de 2020, teve como ponto focal a pandemia da COVID-19. O cenário mundial demandou resiliência política, social e econô-

\footnotetext{
3 Incentivando o grupo a implementar a agenda das Naçóes Unidas para 2030, com foco especial na implementaçáo do ODS 5 (Igualdade de Gênero); bem como da Declaraçáo e Plataforma de Pequim, levando em consideração os Princípios da CEDAW e os Princípios de Empoderamento das Mulheres.
} 
mica. Enquanto a organização se ocupou com as discussões que tratavam das medidas emergenciais para o combate ao novo coronavírus e das medidas necessárias para o aquecimento da economia no mundo pós-pandêmico, o W20 se esforçou para evidenciar o aprofundamento das desigualdades de gênero em meio à pandemia, para estabelecer objetivos que pudessem amenizar essas disparidades, e para recomendar medidas-chave em torno das estratégias de recuperação econômica e de crescimento a longo prazo.

Como fruto da cúpula emergencial, em março de 2020, o W20, em conjunto com o B20 e o L20, ecoaram o compromisso estabelecido pelos líderes do G20 de:

fazer o que for preciso e usar todas as ferramentas políticas disponíveis para minimizar os danos econômicos e sociais da pandemia, restaurar o crescimento global, manter a estabilidade do mercado e fortalecer a resiliência [e] pedir à Organização Internacional do Trabalho (OIT) e à Organização para Cooperação e Desenvolvimento Econômico (OCDE) para monitorar o impacto da pandemia sobre o emprego (B20; L20; W20, 2020, p. 1, tradução nossa $\left.{ }^{4}\right)$.

Reconhecendo que a pandemia impactaria toda a economia mundial, os grupos enfatizaram a dimensão das relaçôes de trabalho, que seria afetada de três formas fundamentais: no número de vagas de trabalho disponíveis; na qualidade do trabalho; e no efeito sofrido por grupos específicos, que estariam mais vulneráveis ao cenário adverso de desemprego e insegurança - em especial as mulheres ${ }^{5}$ (B20; L20; W20, 2020).

4 To do whatever it takes and to use all available policy tools to minimize the economic and social damage from the pandemic, restore global growth, maintain market stability, and strengthen resilience", and to "ask the International Labor Organization (ILO) and the Organization for Economic Cooperation and Development (OECD) to monitor the pandemic's impact on employment.

5 Segundo dados da Secretaria de Estatísticas Trabalhistas dos Estados Unidos (2020), por exemplo, em dezembro de 2020 o país perdeu mais de 140.000 empregos, sendo que todos eles eram ocupados por mulheres. Ainda, as mulheres
Além disso, essa vulnerabilidade fica evidente na composição da "linha de frente contra a COVID", uma vez que as mulheres representam $70 \%$ dos trabalhadores do setor de saúde e de assistência social a nível global. Dessa forma, os grupos de trabalho ressaltaram a necessidade de incorporar medidas para a proteçáo econômica das mulheres, garantido o acesso a auxílios e benefícios; assim como para a segurança das mulheres na linha de frente, como estratégia, inclusive, de garantir acesso a serviços de saúde de qualidade para a população (B20; L20; W20, 2020).

Já na declaração oficial do W20 durante a cúpula de Riade, o grupo afirmou que as estratégias do G20 de recuperação econômica deveriam pavimentar o caminho para uma construção igualitária, na qual as mulheres seriam reconhecidas como atoras centrais, e que fazem parte da solução da crise enfrentada mundialmente. À vista disso, o W20 recomendou oito medidas-chave para apoiar as estratégias de recuperaçáo econômica: 1) assegurar a igualdade de representação nas instâncias de tomada de decisão pública e privada; 2) adotar orçamentos com perspectiva de gênero embasados em avaliaçóes de impacto; 3) aumentar significativamente o investimento em infraestrutura social para gerar empregos e resiliência; 4) implementar mecanismos de proteçáo social e de renda para o emprego informal; 5) desenvolver e financiar planos de ação para estimular a participação das mulheres no empreendedorismo e nos ecossistemas de inovação; 6) aumentar o acesso de mulheres e meninas à tecnologia digital; 7) aumentar o acesso das mulheres a serviços financeiros; 8) financiar a pesquisa de dados desagregados por sexo no curso da pandemia (W20, 2020).

perderam 5,4 milhóes de empregos ao longo de 2020 no país; enquanto os homens perderam aproximadamente 4,4 milhōes de empregos. 
Além disso, tendo em vista a oportunidade de incentivar a adoção de estratégias de crescimento econômico mais equitativas no contexto pós-pandemia, o W20 recomendou medidas-chave para a promoçáo do empoderamento econômico de mulheres a longo prazo. $\mathrm{O}$ conjunto de vinte e duas medidas foram apresentadas a partir de sete eixos que complementam e expandem as recomendaçôes emergências em torno de: 1) reformas legais e sociais; 2) tomada de decisão inclusiva; 3) inclusão equitativa no mercado de trabalho; 4) inclusão financeira; 5) inclusão digital; 6) empreendedorismo feminino; e 7) prestação de contas do G20 (W20, 2020).

Portanto, o W20 reforça as suas principais pautas dos últimos cinco anos, enfatizando a necessidade de se assumir uma lente de gênero para pensar estratégias de crescimento e desenvolvimento econômico, que têm na inclusão das mulheres no mercado de trabalho - a partir da inclusão digital, financeira, política e social - um dos seus principais potenciais para geração de renda e crescimento sustentável. O grupo afirma e clama pela liderança do G20 na incorporação dessa agenda tanto nas medidas de cunho emergencial, no contexto da crise econômica global atual, quanto na perspectiva de construçôes equitativas a longo prazo.

\section{Limites e avanços da agenda no âmbito do G20}

Apesar dos esforços do W20 em exortar os líderes do G20 a honrarem e agirem de acordo com os compromissos assumidos nas cúpulas anteriores, a fim de se promover a igualdade de gênero (W20, 2020), muitas das pautas que guiam a agenda sobre o tema na organização permaneceram paralisadas na cúpula de 2020. Em especial, a meta de Brisbane, assumida na cúpula de 2014, que estabelece o compromisso $25 \times 25$, segue sem medidas para estimular o seu cumprimento. Sem a criação de planos nacionais e sem estratégias claras para acelerar o ritmo de implementação da meta, dificilmente será possível reduzir o gap de participação feminina no mercado de trabalho em 25\% até 2025 (W20, 2020; PREYMA, 2020).

A Declaração dos Líderes de 2020, que sintetiza a agenda e os compromissos assumidos na cúpula de Riade, ainda que sinalize para a continuidade da promoção da igualdade de gênero e de esforços para remover as barreiras à participação econômica e ao empreendedorismo das mulheres, não se compromete como nenhuma medida concreta. A única iniciativa a ganhar destaque na declaração foi a Aliança para o Empoderamento e Progressão da Representação Econômica das Mulheres (EMPOWER), que diz respeito a alianças do setor privado para estimular a presença feminina em posições de liderança e que realizou o seu primeiro encontro durante a presidência saudita. Além disso, o B20, em colaboração com o W20, criou o Conselho de Açáo da Mulher Empresarial, com a intenção de contribuir para a promoção da participação das mulheres no mercado de trabalho e a sua representação em cargos de liderança (PREYMA, 2020; G20, 2020).

Já iniciativas que, anteriormente, foram acompanhadas de açóes concretas por parte das lideranças políticas do G20, estimulando a criação de emprego, geração de renda e crescimento econômico, como a Iniciativa Financeira para Mulheres Empresárias (We-Fi) e a Iniciativa de Inclusão e Educação Digital (\#eSkills4Girls), não ganharam destaque. De modo que o diálogo com o W20 parece ter sido menos intenso do que em cúpulas anteriores, como a de Hamburgo, em 2017, ou a de Buenos Aires, em 2018. 
Por outro lado, reconhecendo que as mulheres são desproporcionalmente afetadas pela pandemia da COVID-19 em termos de emprego, renda e como provedoras de saúde e cuidado, os líderes do G20 se prometeram a elaborar, até meados de 2021, regras para a tributação justa da economia digital em expansão, e a oferecer estratégias para lidar com a crescente segregação digital como consequência das políticas de distanciamento social e lockdown (KIRTON, 2020). O entendimento de que a exclusão digital de mulheres impacta a saúde, a educação e a sua participaçáo no mercado de trabalho é um passo importante para fortalecer açóes existentes e para a criação de novas estratégicas para a promoção da igualdade econômica de gênero.

Assim, apesar do G20 ter ecoado importantes discussóes realizados no âmbito do W20 - como em relação ao aprofundamento de desigualdades de gênero como decorrência da pandemia, à necessidade de se promover o empoderamento econômico de mulheres como forma de angariar recuperação econômica e à importância da promoção da inclusão digital - as recomendaçôes, metas e açóes propostas nos documentos do W20 não foram incluídas na declaração oficial dos líderes. A limitação em assumir compromissos objetivos mais uma vez esvaece a potencial do grupo de liderar a governança global da promoçáo da igualdade econômica de gênero.

\section{Considerações finais}

O W20 conseguiu pautar, nos últimos cinco anos, uma agenda para a promoção da igualdade econômica de gênero no âmbito do G20. Em consonância com a ONU, com o Fórum Econômico Mundial e com o Banco Mundial, o G20 assumiu o empoderamento econômico de mulheres como sendo um fator essencial para a superação da desigualdade, da pobreza e para a promoçáo do desenvolvimento sustentável. Em meio à pandemia da COVID-19, as disparidades de gênero foram encaradas, mais uma vez, como um problema que precisa ser abordado por meio de estratégias para a inclusão financeira, digital e pela maior participação de mulheres nas instâncias de poder e decisão, na direção de superar essas barreiras sistêmicas.

Os limites, portanto, não parecem ser fruto de uma falta de coerência dos discursos em torno da agenda para o empoderamento econômico de mulheres, mas sim de uma paralisia de ações, estratégias e mecanismos para prestação de contas por parte da organização. Mais urgentemente, está posto o desafio para a presidência italiana, que terá a missão de facilitar o estabelecimento de açôes para a implementação o acompanhamento da meta $25 \times 25$ de Brisbane, durante a cúpula de Roma de 2021.

\section{Referências}

AL-RASHEED, Madawi. A Most Masculine State: Gender, Politics and Religion in Saudi Arabia. Cambridge: Cambridge University Press, 2013.

B20; L20; W20. Joint Statement on Employment, Skills \& Women. Riade. 5 abr. 2020. Disponível em: http://www.g20. utoronto.ca/b20/B20-L20-W20-final-statement-2020.pdf. Acesso em: 24 jan. 2021.

G20. Riyadh Summit Leaders' Declaration. Riade. 22 nov. 2020. Disponível em: https://www.gov.br/mre/en/contact-us/ press-area/press-releases/g20-riyadh-summit-leaders2019-declaration. Acesso em: 24 jan. 2021.

KIRTON, John. A Significant Short-Term Success: Promising Prospects for the G20 Riyadh Summit. G20 Research Group. Toronto: University of Toronto, 18 nov. 2020. Disponível em: http://www.g20.utoronto.ca/analysis/201118-kirton-prospects.html. Acesso em: 24 jan. 2021.

KULIK, Julia. G20 Gender Policy Accountability. G20 Research Group. Toronto: University of Toronto, 2015. Disponível em: http://www.g20.utoronto.ca/analysis/151113-kulik. html. Acesso em: 24 jan. 2021.

MEIJER, R. The Gender Segregation (ikhtilāđ) Debate in Saudi Arabia: Reform and the Clash between $\nabla U$ Ulamā⿴囗 and Liberals. Journal for Islamic Studies, v. 30, 2010.

MOODY, Joanna. Engagement or obligation: The G20's commitment to gender equality. Global Policy. The University of Sheffield, 2015. Disponível em: http://www.global- 
policyjournal.com/sites/default/files/inline/files/Moody\%20 -\%20Engagement $\% 20$ or\%20obligation, \%20The $\% 20$ G20\%E2\%80\%99s\%20commitment $\% 20$ to\%20gender $\% 20$ equality.pdf. Acesso em: 24 jan. 2021.

PREYMA, Lida. Women's Empowerment at the G20 — Maybe Next Year. G20 Research Group. Toronto: University of Toronto, 22 nov. 2020. Disponível em: http://www.g20.utoronto. ca/analysis/201122-preyma.html. Acesso em: 24 jan. 2021.

SECRETARIA DE ESTATÍSTICAS TRABALHISTAS. Estados Unidos da América. Effects of COVID-19 Pandemic on Employment and Unemployment Statistics. The Bureau of Labor Statistics (BLS), 2020. Disponível em: https://www.bls. gov/covid19/effects-of-covid-19-pandemic-on-employment-and-unemployment-statistics.htm. Acesso em 24 jan. 2021.

VÁZQUEZ, L. Roldán. La cuestión de género en el G20 y la estrategia de la transversalidad. Debates Latinoamericanos, v. 17, n. 34, 2019.

WATSON-LYNN, Erin. Saudi Arabia is not offside on gender equality. The Interpreter. Lowy Institute: 06 mar. 2020. Disponível em: https://www.lowyinstitute.org/the-interpreter/saudi-arabia-not-offside-gender-equality. Acesso em: 24 jan. 2021.

W20. Communiqué W20 2020. Riade: 2020. Disponível em: https://drive.google.com/file/d/16WkRnv7r-6oZz5LZL7Z_06sTD2FKKbAT/view. Acesso em: 24 jan. 2021. 